\title{
Burkina Faso: Mejorar la atención postaborto beneficia a pacientes y proveedores
}

Frontiers in Reproductive Health

Follow this and additional works at: https://knowledgecommons.popcouncil.org/departments_sbsr-rh

Part of the International Public Health Commons, Public Health Education and Promotion Commons, and the Women's Health Commons How does access to this work benefit you? Let us know!

\section{Recommended Citation}

"Burkina Faso: Mejorar la atención postaborto beneficia a pacientes y proveedores," FRONTERAS Resúmenes de Investigación Operativa. Ciudad de México: Population Council, 2000. 


\section{Burkina Faso Atención postaborto}

Resumen de 102

\section{Mejorar la atención postaborto beneficia a pacientes y proveedores}

\begin{abstract}
La capacitación del personal hospitalario para mejorar la atención médica de urgencia para mujeres con complicaciones por abortos espontáneos o inducidos mejora la atención que reciben las pacientes, reduce la estancia hospitalaria y los costos, y aumenta el uso de anticonceptivos. La anestesia local es esencial para el control del dolor. Los médicos capacitados en atención postaborto han adiestrado a otros equipos médicos de Burkina Faso, así como de Senegal, Guinea y Haití. Los funcionarios de salud de otros países de África Occidental han manifestado interés en este tipo de capacitación.
\end{abstract}

\section{Antecedentes}

A solicitud de la Dirección de Salud Familiar del Ministerio de Salud (MS), la Red de Investigación en Salud Reproductiva (CRESAR) realizó de 1996 a 1998 un estudio para incorporar la atención de urgencia para mujeres con complicaciones derivadas de un aborto espontáneo o un aborto inducido inapropiadamente (aborto inseguro). Gracias a la asistencia técnica del Population Council y de JHPIEGO, CRESAR capacitó al personal de dos grandes hospitales ubicados en Uagadugú y Bobo Diulaso en la prestación de servicios de atención postaborto (APA). El programa de capacitación para médicos, enfermeras y parteras incluyó la aspiración manual endouterina (AMEU), los métodos de planificación familiar, la prevención de infecciones y la comunicación con las pacientes. Dichos proveedores participaron también en el desarrollo de normas y estándares para servicios de APA.

Con el objeto de medir los cambios en conocimientos y comportamiento, CRESAR entrevistó a 330 pacientes con complicaciones derivadas de un aborto y a 78 proveedores antes de la intervención, y a 456 pacientes y a 41 proveedores después de la intervención. Se recopiló también información sobre costos hospitalarios.

\section{Resultados}

La satisfacción de las pacientes fue significativamente mayor después de la introducción

\section{Extensión de la intervención}

Durante el estudio piloto, el MS, CRESAR y los proveedores de servicios de los dos hospitales participantes redactaron las normas nacionales para la atención postaborto. Las normas detallan los componentes esenciales de servicios APA de calidad, como son los procedimientos para la prevención de infecciones y los servicios rutinarios de consejería para las pacientes. EI MS adoptó estas normas y ha empezado a extender los servicios a los hospitales regionales.

\section{Los cuatro médicos capacitados} durante este estudio han adiestrado a equipos médicos de hospitales regionales de Burkina Faso, así como a proveedores de Senegal, Guinea y Haití. Los funcionarios de salud de otros países de África Occidental han manifestado interés en este tipo de capacitación. 
de servicios mejorados de APA. La mayoría de las pacientes declaró que los proveedores respondieron a sus preguntas con buena disposición y dieron explicaciones e instrucciones claras. Casi todas las pacientes (94 por ciento) recibieron consejería sobre planificación familiar. Después de recibir este servicio, 83 por ciento de las pacientes aceptaron un método anticonceptivo, mientras que antes de la intervención sólo 57 por ciento aceptó un método.

Ofrecer únicamente palabras tranquilizadoras no basta para controlar el dolor durante la realización de la AMEU. El uso de anestesia local es esencial.

Los proveedores adoptaron la AMEU como el tratamiento preferido para la atención postaborto. Este procedimiento, comparado con los procedimientos clínicos usados anteriormente, redujo los costos tanto para el hospital como para las pacientes debido a la disminución del tiempo de estancia hospitalaria, de la frecuencia de uso de la anestesia general y del tiempo empleado por los proveedores.

\section{Implicaciones normativas}

Para la expansión de los servicios de APA, se debería hacer especial énfasis en la calidad de la atención y en su relación con los servicios de planificación familiar. Se deberían incluir en los presupuestos hospitalarios los costos de equipo para la AMEU y de otros suministros necesarios.

Los hospitales participantes en los estudios pueden desempeñar un papel esencial como centros de referencia, capacitación y estudio para otros proveedores.

\section{Beneficios de la atención postaborto mejorada}

\begin{tabular}{lcc}
\hline & $\begin{array}{c}\text { Antes de la } \\
\text { capacitación }\end{array}$ & $\begin{array}{c}\text { Después de la } \\
\text { capacitación }\end{array}$ \\
\hline $\begin{array}{l}\text { Tiempo empleado por los proveedores } \\
\text { en el tratamiento de urgencia (minutos) }\end{array}$ & 73 & 23 \\
\hline $\begin{array}{l}\text { Duración de la estancia hospitalaria (horas) } \\
\text { Costo para la paciente (USD) }\end{array}$ & 36 & $\$ 19$ \\
\hline $\begin{array}{l}\text { Pacientes informadas sobre el regreso inmediato } \\
\text { de la fecundidad }\end{array}$ & $\$ 34$ & $90 \%$ \\
\hline \begin{tabular}{l} 
Pacientes que recibieron un método de PF \\
\hline
\end{tabular} & $57 \%$ & $83 \%$ \\
\hline
\end{tabular}

Febrero 2000

Ministry of Health, Burkina Faso, 1988. Introduction of Emergency Medical Treatment and Family Planning Services for Women with Complications from Abortion in Burkina Faso. Para obtener más información, escriba o llame a: Population Council-Oficina Regional para América Latina y el Caribe. Escondida 110, Villa Coyoacán, 04000, México, D.F. México. Tel. (52) 55-54-03-88; Fax: (52) 55-5412-26. Correo electrónico: disemina@popcouncil.org.mx.

Este proyecto fue posible gracias al apoyo de la Agencia de los Estados Unidos para el Desarrollo Internacional (USAID) bajo el contrato numero CCP-3030-C-00-3008-00 y el Acuerdo de Cooperación número HRN-A-00-98-00012-00 